\title{
Formative research to develop an intervention for addressing mental health/psychosocial issues and HIV vulnerability of marginalized adolescents in Addis Ababa, Ethiopia
}

Nrupa Jani

Population Council

Katie D. Schenk

Population Council

Follow this and additional works at: https://knowledgecommons.popcouncil.org/departments_sbsr-hiv

Part of the Demography, Population, and Ecology Commons, Family, Life Course, and Society Commons, International Public Health Commons, and the Maternal and Child Health Commons How does access to this work benefit you? Let us know!

\section{Recommended Citation}

Jani, Nrupa and Katie D. Schenk. 2014. "Formative research to develop an intervention for addressing mental health/psychosocial issues and HIV vulnerability of marginalized adolescents in Addis Ababa, Ethiopia." Washington, DC: Population Council. 
$\underline{\underline{\underline{\underline{\underline{E}}}} Q}$ PEPFÁR

\section{FORMATIVE RESEARCH TO DEVELOPAN} INTERVENTION FOR ADDRESSING MENTAL HEALTH/PSYCHOSOCIAL ISSUES AND HIVVULNERABILITY OF MARGINALIZED ADOLESCENTS IN ADDIS ABABA, ETHIOPIA

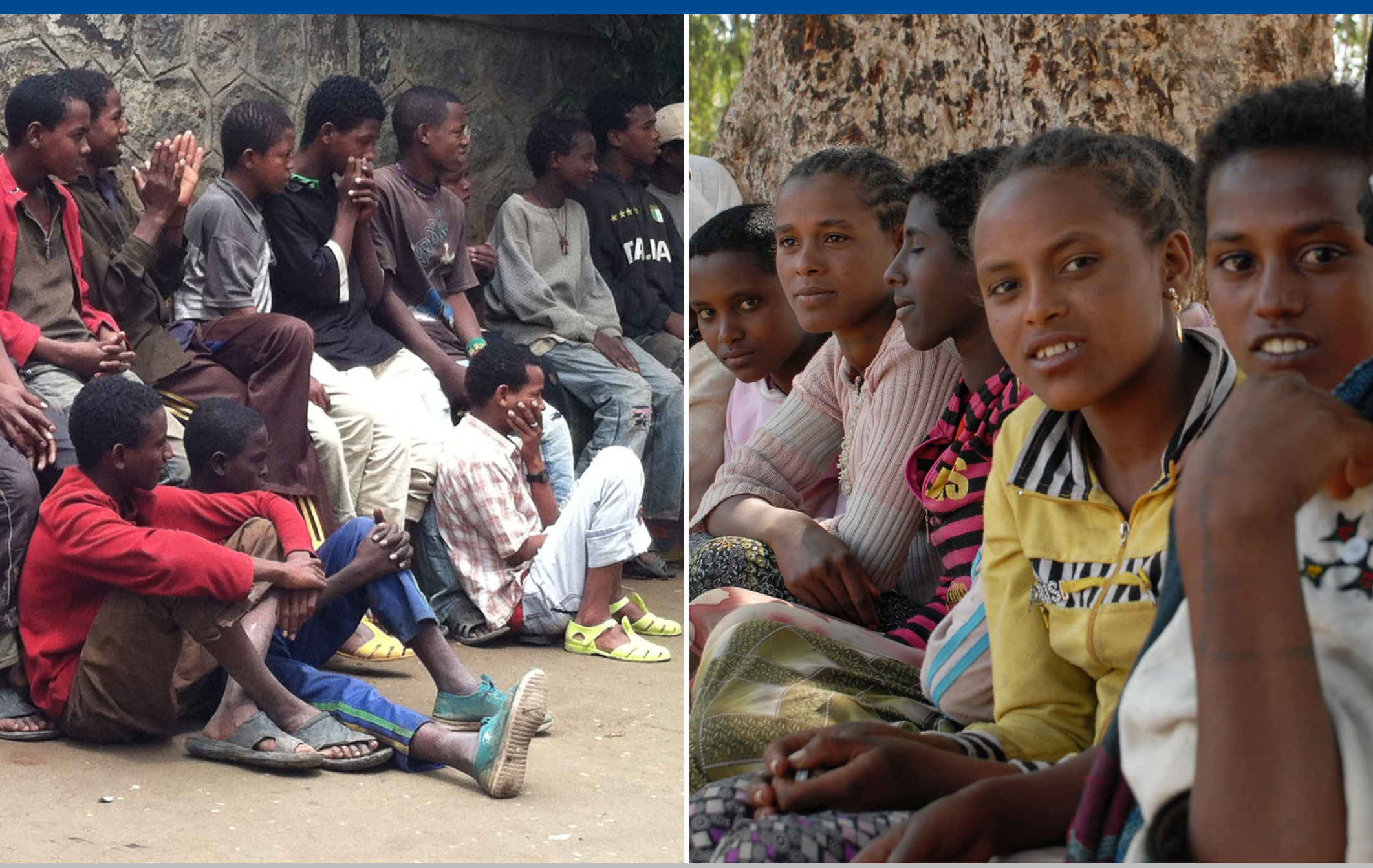



FORMATIVE RESEARCHTO

DEVELOP AN INTERVENTION

FOR ADDRESSING MENTAL

HEALTH/PSYCHOSOCIAL ISSUES

AND HIV VULNERABILITY OF

MARGINALIZED ADOLESCENTS

IN ADDIS ABABA, ETHIOPIA

NRUPA JANI AND KATIE SCHENK

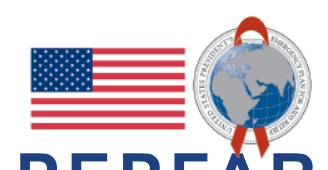

PEPFAR

W USAID Project SEARCH

HIVCpre 


\section{ACKNOWLEDGMENTS}

We would like to first and foremost thank all the Biruh Tesfa and Retrak participants of this study. This study would not have been possible without the guidance of the principal investigator, Sam Kalibala, and the Population Council-Addis research team, including Annabel Erulkar, Gebeyehu Mekonnen, Ayenachew Kerie, and Aster Tefera. We greatly appreciate the work of our Retrak colleagues, Lynn Kay and Julyata Shibru, as well as our lead psychologist, Lake Bedilu, and psychometrician, Kassahun Habtamu, who assisted with both the design and implementation of the study. We are also grateful to all the Biruh Tesfa mentors and Zelalem Belay for their assistance in implementing the study and coordinating the data collection efforts, the government of Ethiopia, and the community members at large who support the implementation of both these programs.

Our special thanks also go to our USAID Mission colleagues including Tsegaye Tilahun and Renee Demarco, and the HIVCore management team at USAID/Washington, Sarah Sandison and Glenn Post, for their leadership. Lastly, HIVCore would like to acknowledge the reviewers who provided detailed technical input that substantially transformed the document: Sam Kalibala (HIVCore/Population Council), Karen Foreit (HIVCore/Futures Group), Annabel Erulkar (Population Council), Julie Pulerwitz (Population Council), and Lynn Kay (Retrak).
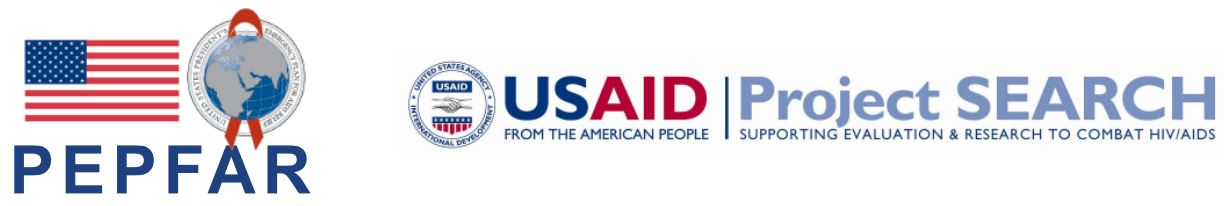

This report was made possible through support provided by the President's Emergency Plan for AIDS Relief and the U.S. Agency for International Development (USAID) via HIVCore, a Task Order funded by USAID under the Project SEARCH indefinite quantity contract (Contract No. AID-OAA-TO-11-00060).

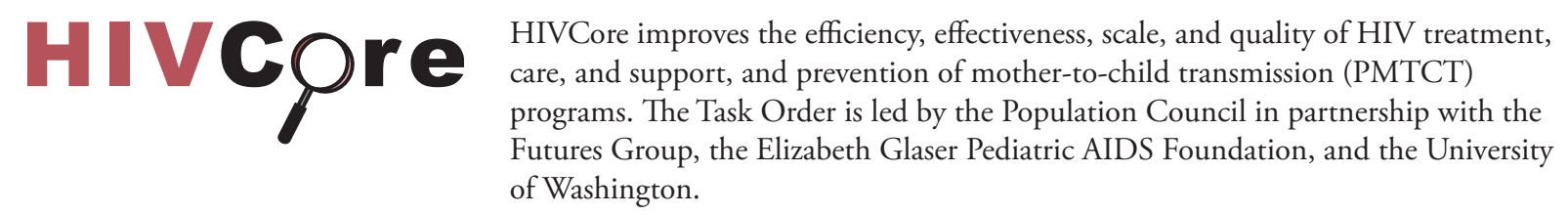

Published in May 2014. (C2014. The Population Council Inc.

Cover photo credits: Left photo, Nrupa Jani/Population Council; Right photo, Zeleman Productions, courtesy of the Population Council.

Suggested citation: Jani, Nrupa and Katie Schenk. 2014. "Formative research to develop an intervention for addressing mental health/psychosocial issues and HIV vulnerability of marginalized adolescents in Addis Ababa, Ethiopia," HIVCore Formative Report. Washington, DC: USAID | Project Search: HIVCore. 


\section{TABLE OF CONTENTS}

\section{ACRONYMS}

EXECUTIVE SUMMARY

STUDY BACKGROUNDIAIMS 3

HIV in Ethiopia

HIV and rural-urban migration of young people 3

Living conditions, psychological issues, and HIV risks among young people 4

Existing service delivery programs

$\begin{array}{ll}\text { Objective } & 6\end{array}$

$\begin{array}{ll}\text { METHODS } & \mathbf{7}\end{array}$

$\begin{array}{ll}\text { Sample recruitment and study population } & 7\end{array}$

$\begin{array}{ll}\text { Data management and analysis } & 7\end{array}$

Ethical considerations $\quad 8$

$\begin{array}{lr}\text { Study limitations } & 8\end{array}$

RESULTS 9

Sexual abuse among vulnerable migrant adolescents leads to psychological trauma $\quad 10$

Social isolation compromises mental health status of marginalized migrant youth 13

Causes and outcomes of rural to urban youth migration are consistent with

existing literature $\quad 15$

Likely under reporting of sexual experiences $\quad 17$

Varying levels of knowledge and attitudes about HIV 18

Reported gaps in current service provision and suggestions for improvement 19

$\begin{array}{ll}\text { DISCUSSION } & 23\end{array}$

EVIDENCE INFORMING INTERVENTION 25

Study-specific recommendations for a targeted psychosocial intervention 25

Broader recommendations for government and stakeholders 27

$\begin{array}{lr}\text { REFERENCES } & 29\end{array}$

APPENDICES 31

Annex A-Service recipient in-depth interview guide 31

Annex B-Service providers in-depth interview guide 37 


\section{ACRONYMS}

CSA

HIV

IDI

NGO

OPRIFS

STI

USAID
Child Sexual Abuse

Human Immunodeficiency Virus

In-depth Interview

Non-governmental Organization

Organization for the Prevention, Rehabilitation and Integration of Female Street Children

Sexually Transmitted Infection

United States Agency for International Development 


\section{EXECUTIVE SUMMARY}

Children and adolescents who migrate from rural regions to Addis Ababa, Ethiopia often flee their households to escape from abusive families, forced marriages, poverty, lack of economic opportunity and education, and other social problems. More often than not they are met with equally harsh, if not worse, challenges when they arrive in Addis Ababa, including treacherous living situations, abusive working conditions with meager compensation, limited opportunities for education and socialization, and absence of family support.

\section{OBJECTIVE AND METHODS}

The objective of this study was to conduct a qualitative needs assessment to determine the type and extent of mental health and psychological needs among adolescent migrants living in Addis Ababa in order to develop a targeted psychosocial support intervention to address the identified needs. Semi-structured indepth interviews (IDIs) were conducted with 30 service recipients from Biruh Tesfa and Retrak, 15 girls and 15 boys respectively, and 11 service providers from Biruh Tesfa, Retrak, and OPRIFS (Organization for the Prevention, Rehabilitation and Integration of Female Street Children).

\section{KEY FINDINGS}

Key findings from this study revealed several high risk situations that adolescent migrants in Addis Ababa are exposed to that specifically compromise their psychosocial well-being and increase their vulnerability to HIV.

First, sexual abuse among vulnerable migrant adolescents leads to psychological trauma and HIV risk.

Second, social isolation, due to being overworked and separated from family and friends, compromises their mental health status.

Third, causes and outcomes of migration were found to be consistent with current literature. Boys reported migrating to Addis Ababa mainly to seek further education, escape family conflict at home, or to earn money for themselves or siblings, often following the death of a parent. Upon arriving in Addis Ababa many boys reported feeling happy due to the freedom from authority that comes with living on the street. Girls reported that their parents/guardians were denying them educational opportunities. Some left their homes to escape unwanted, early marriage.

Fourth, there are inconsistencies between what service providers report or perceive about the sexual behavior of their service recipients and what the service recipients report about their own sexual behavior. These inconsistencies include an apparent under reporting of sexual experiences overall among boys and girls. This is in contrast to reports by service providers of high risk behavior among boys despite their acknowledging the associated risks.

Lastly, service recipients demonstrated varying levels of knowledge and attitudes about HIV, with some displaying very detailed levels of understanding about HIV prevention methods while others seemed to be misinformed about HIV risks and transmission modes. 


\section{RECOMMENDATIONS}

Based on the findings of this study an expert committee recommended the implementation of an intervention to address the psychosocial needs of marginalized adolescents. This intervention will consist of individual counseling sessions; targeted group counseling sessions; a series of art therapy and creative therapy sessions known as music, drama, dance therapy; and community engagement events.

While this formative study was designed to inform the psychosocial intervention to be tested in the third phase of the study, the expert committee also made broader recommendations for a wider group of stakeholders, including the government of Ethiopia, to consider for future programming, as they fall outside of the scope of the intervention of this study. These suggestions include implementing family and community education efforts focusing on developing parenting and conflict resolution skills, and strengthening law enforcement and social and economic support to ensure a comprehensive response to the problems of migrant children in Addis Ababa.

The findings from the needs assessment presented here comprise the first phase of this three-phase study. The second phase of this study will adapt a psychometric screening tool and test it for reliability and validity among the same target population. Findings from this needs assessment will be used to develop a psychosocial intervention to be administered to the same target population during the third phase of this study. 


\section{STUDY BACKGROUNDIAIMS}

\section{HIV IN ETHIOPIA}

While its HIV prevalence rate is one of the lowest in sub-Saharan Africa (1.5 percent among 15-49 year olds) due to its large population size, Ethiopia ranks tenth in the region in terms of numbers of people living with HIV (EDHS 2011; UNAIDS 2013). Nearly 800,000 people are currently living with HIV, while the incidence rate of new infections is increasing among groups and geographical regions that previously held low rates, necessitating the need to target select groups, including young people (UNAIDS 2012). Despite declining HIV prevalence among youth ages 15-24 in recent years (UNAIDS 2012), data show that young women remain at greater risk for HIV infection than young men. The most at-risk populations for HIV in Ethiopia include domestic workers, waitresses, and male daily laborers.

HIV prevalence rates are also higher in urban areas ( 4.2 percent) than rural areas (0.6 percent) (EDHS 2011), with the rate of new infections actually increasing in smaller towns that serve as a bridge to further spread the disease to rural areas (UNAIDS 2012). The geographical disparity of the epidemic emphasizes the need to pay special attention to rural to urban migration patterns in order to expand HIV prevention efforts.

\section{HIV AND RURAL-URBAN MIGRATION OFYOUNG PEOPLE}

Over the last several decades Ethiopia has seen a steady increase in rural to urban migration (Erulkar et al. 2006). Every year, thousands of Ethiopian youth migrate to urban areas, often in search of educational or work opportunities, but also to escape hardships in their rural homes. Principal reasons for adolescent migration among Ethiopian males and females include school and work aspirations and marriage (Temin et al. 2013). Many female migrants often have little to no education (Erulkar and Ferede 2007). Upon migrating, many adolescent girls take employment as domestic workers, working for very low wages for long hours with limited opportunity for socializing. The resulting social exclusion leads to having fewer friends than other adolescents, lower self-esteem, and lower levels of HIV knowledge (Erulkar and Ab Mekbib 2007) and puts them at risk of coerced and/or transactional sex (Erulkar and Ferede 2007). Migrant girls are more likely than boys to become trafficking victims or fall into sexual exploitation because of the gender norms that allow males to undervalue and dominate females (Temin et al. 2013).

Young migrant boys in Ethiopia are in a similarly precarious situation. The majority of young boys who migrate to larger cities live on the street with no firm guardian or place of residence. Oftentimes they have experienced the trauma of an adverse family situation, such as the death or abandonment of a parent(s) or suffered physical or sexual abuse, which led them to flee the home or be pushed away. Once on the street and disconnected from the protection of their family and community they are likely to suffer further trauma (Kay 2012). Sexual abuse and exploitation of male children is increasing in Addis Ababa. Tadele (2009) found that 29 percent of male street children in the Merkato area of Addis Ababa had been sexually abused. Twenty-six percent of reported cases of sexual abuse in Addis Ababa in 2004 were street children (Hagos 2006). It is assumed that the majority of these abuse cases remain un-reported, 
under-reported, or misreported due to a widespread public and religious beliefs that claim men who have sex with men or male sexual abuse are not "Ethiopian" (Tadele 2009). The same study also found that a fourth of the sexually abused male street children reported being abused by their friends/peers who were formerly or are currently also street boys (Tadele 2009). Given that the perpetrators could also have been sexually abused at some point, this could support the phenomenon that victims of sexual abuse are likely to perpetuate this abuse later in life.

\section{LIVING CONDITIONS, PSYCHOLOGICAL ISSUES,AND HIV RISKS AMONG YOUNG PEOPLE}

Designing interventions to address the mental health and psychosocial problems of children and adolescents requires understanding the environment of the child/adolescent, including his/her family and community. Specific situations, including economic and psychosocial adversity, exposure to violence or conflict, voluntary or forced migration, effects of HIV/AIDS, as well as the perceived "rights" of a child/ adolescent in a particular society can facilitate a mental health disorder (WHO 2003).

In order to promote positive social participation and individual well-being, identifying and treating mental health problems early in development is highly recommended (WHO 2003). Poor living conditions are strongly associated with mental health difficulties (WHO 2003; Ashenafi et al. 2000; Desta 2008), especially among marginalized and vulnerable populations. Vulnerable children may engage in risky sexual behavior or may be at increased risk of becoming victims of sexual violence and exploitation, both of which predispose them to HIV infection. Early emotional and physical abuse can impair optimal cognitive and emotional development in children and adolescents (Andrés et al. 1999) which can lead to increased risk of mental and behavioral disorders (Last et al. 1996). Thus, it is critical to identify and address mental health problems as early as possible to avoid negative social and health outcomes for youth. These social outcomes range from separation from primary caregivers, addiction to harmful substances, and increased risk-taking behaviors, such as drug and alcohol abuse and multiple sexual partners (WHO 2008), all of which can predispose young people to HIV infection. A compromised mental health status can also interfere with an adolescent's ability to acquire and use information about HIV/AIDS, which can increase risk-taking behaviors or impact the young person's ability to practice safe behaviors (WHO 2008).

Poverty is also known to be a central cause of increased vulnerability of children to sexual exploitation and abuse (Yntiso et al. 2009). Poverty increases the likelihood of experiencing adverse conditions such as psychological distresses. Disadvantaged financial conditions can lead to increased risk-taking behaviors such as drug and alcohol abuse as well as the adoption of risk behaviors such as prostitution. Van Blerk and colleagues found that brokers in Ethiopia idle at bus stations waiting for migrant youth travelling to Addis Ababa and often take advantage of girls' fear and poverty to bind them into sex work (Van Blerk 2008). Factors associated with poverty including disadvantaged living and employment conditions can put adolescents in harm's way for known risk factors for HIV transmission, as well as putting them at risk for mental health and psychosocial problems which can also lead to increased HIV risk over and above the risks posed directly by impoverished living and employment conditions.

The premise for this study is illustrated in Figure 1. 


\section{Figure I.Study Logic Model*}

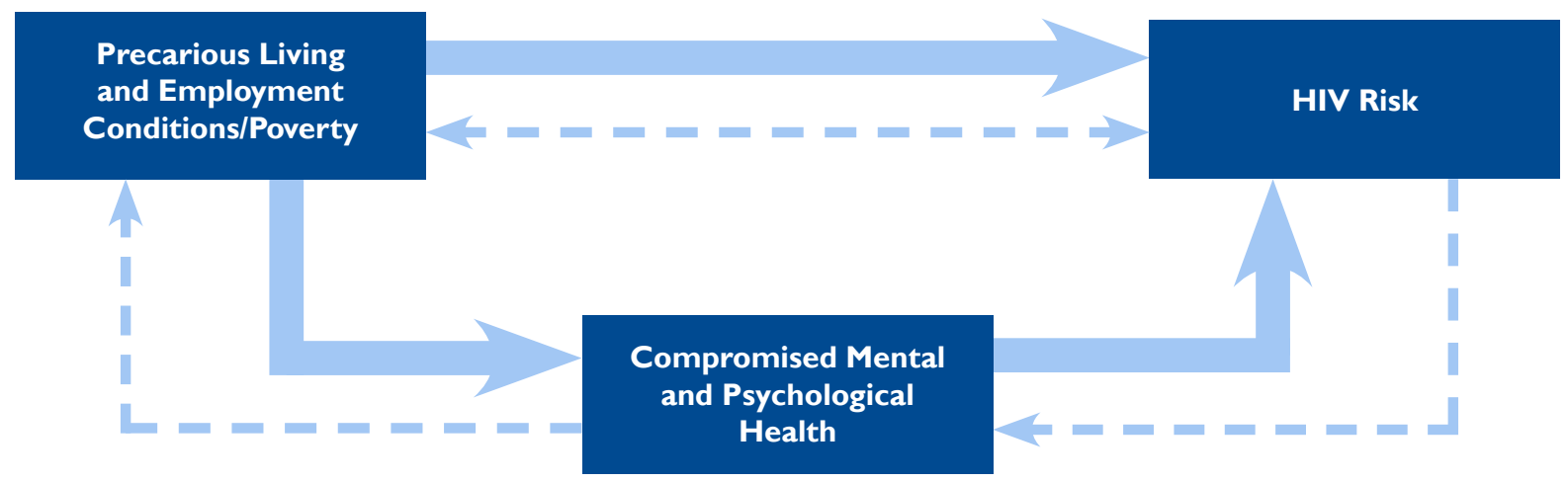

*While the relationships between these three factors are bidirectional this study only focuses on interventions that interrupt the solid, blue arrows

\section{EXISTING SERVICE DELIVERY PROGRAMS}

The Population Council office in Ethiopia in partnership with the Regional Bureaus of Women Children and Youth Affairs operate the Biruh Tesfa (Amharic for "Bright Future") program aimed at addressing HIV risk among migrant girls aged 7-24 years by providing support to these vulnerable girls living in the urban areas of Amhara region and Addis Ababa, as well as migrant girls living in feeder communities in Amhara-those along transport corridors with access to urban centers in Amhara. Biruh Tesfa offers basic education, life skills training, mentoring, and referral services to counselors, psychologists, and medical staff. Education, life skills training, and mentoring sessions take place in locally donated community spaces. Biruh Tesfa partners with the Organization for the Prevention, Rehabilitation and Integration of Female Street Children (OPRIFS), which offers shelter, medical care, and reproductive health services to girls who are victims of violence, frequently by an employer or family member. Victims also receive counseling and legal support, and benefit from the friendship of other girls in the shelter. Mentors from Biruh Tesfa refer their beneficiaries to OPRIFS for counseling services as needed.

The international nongovernmental organization (NGO) Retrak works with street boys aged 7-18 years across Ethiopia, offering alternative options to street life. The organization uses preventative interventions to address root causes that force boys to move to the streets. Retrak seeks to empower boys and help them access their basic rights such as healthcare, shelter, and protection. Through counselors, nurses, teachers, and psychologists, Retrak reaches out to street boys to offer various forms of social, psychological, and medical support, including food, medical care, and shelter. Retrak's primary goal is to enable street boys to achieve a stable family environment, either by returning to their own family if possible, joining a foster family, or integrating into independent living in the community.

Both programs provide critical psychosocial support for vulnerable young people. However, they have not had the opportunity to conduct systematic research regarding the specific psychological problems faced by migrant adolescents. A better understanding of the nature and types of psychological and mental health problems experienced by these vulnerable adolescents would help the organizations strengthen the range of psychosocial services they provide. 
With support from the United States Agency for International Development (USAID) and under the HIVCore task order, the Population Council's Biruh Tesfa program, in collaboration with Retrak Ethiopia, conducted a needs assessment to gauge the level of mental health and psychological problems of vulnerable girls and boys in Addis Ababa. The purpose of this needs assessment was to design a psychosocial support intervention that specifically addresses the psychological and mental health needs identified among the beneficiaries that will be implemented in a subsequent intervention study (which will be reported at a later date).

\section{OBJECTIVE}

The objective of this study was to conduct a qualitative needs assessment to determine the type and extent of mental health and psychological needs among adolescent migrants living in Addis Ababa in order to develop a targeted psychosocial support intervention to address the identified needs.

The terms "adolescents" and "children" are used interchangeably throughout this report. It should be noted, however, that the adolescents interviewed in this study were aged 15-24, as this was the age range approved for this study by the Institutional Review Boards as outlined in the Ethical Considerations section.

This needs assessment comprises the first phase of this three-part study. The second phase of this study will adapt a psychometric screening tool and test it for reliability and validity among the same target population, which will be used for identifying those in need of psychological and mental health care. Findings from the needs assessment will be used to develop a psychosocial intervention to be tested in the same target population during the third phase of this study. This report presents findings from the first phase. 


\section{METHODS}

\section{SAMPLE RECRUITMENT AND STUDY POPULATION}

This was a qualitative study conducted during August to September 2012 among clients and staff of two organizations delivering services to vulnerable girls (Biruh Tesfa) and boys (Retrak) in Addis Ababa, as well as staff of Biruh Tesfa's partner, OPRIFS. Semi-structured in-depth interviews (IDIs) were conducted with 30 service recipients from Biruh Tesfa and Retrak, 15 girls and 15 boys respectively, and 11 service providers from Biruh Tesfa, Retrak, and OPRIFS. This sample size was chosen since there tends to be no added benefit in using larger sample sizes for qualitative data given that saturation of ideas occurs after a few interviews. Thus it is more important for the researcher to spend more time conducting in-depth analysis of a few interviews than to administer a large number of interviews (Crouch and McKenzie 2006). The sampling strategy was purposive. The study team chose service recipients using data from service registers at Biruh Tesfa and Retrak, ensuring a breadth of respondent characteristics based on the eligibility criteria.

Eligibility criteria for service recipients study inclusion were:

- Between the ages of 15-24 years.

- Participating in the Biruh Tesfa or Retrak program taking place in three weredas (6, 7, and 9) or subcity neighborhoods in Addis Ababa.

- Receiving services from his/her respective organization for at least three months.

- Ability to provide informed consent.

The only eligibility criterion for service providers was that they had been working at the respective organization for at least six months.

The IDIs with both service recipients and service providers covered the following topics: demographics, living conditions, family and migration history, education and work history, range of services received/ offered, risk taking behavior, history of abuse, sexual experiences, psychosocial well-being, and future goals/desires. See Annex A and B for a copy of study questionnaires for both service recipients and service providers.

\section{DATA MANAGEMENT AND ANALYSIS}

All interviews were conducted in Amharic, audio recorded, transcribed, and then translated into English in preparation for data analysis. Transcripts were reviewed by Population Council researchers on an ongoing basis and all queries were resolved prior to importing the transcripts into ATLAS.ti (Version 7.0) qualitative research software. Once transcripts were coded, analysts used a modified framework analysis methodology to explore key themes that emerged from the data (Green and Thorogood 2004). 


\section{ETHICAL CONSIDERATIONS}

The study protocol, instruments, and informed consent forms were reviewed and approved by the Institutional Review Board of the Population Council and the Addis Ketema Sub-City Health Office. All participants provided written informed consent. Research activities involving adolescents followed guidance outlined in Ethical Approaches to Gathering Information from Children and Adolescents in International Settings: Guidelines and Resources (Schenk and Williamson 2005).

\section{STUDY LIMITATIONS}

The qualitative data gathered from the IDIs came from a convenience sample of service recipients and providers. It is possible that beneficiaries and providers who agreed to be interviewed felt strongly satisfied or dissatisfied about the services being provided at his/her organization and wanted to share those particular experiences with the interviewers. Reporting bias may also have affected the reporting, or lack thereof, of socially sensitive or stigmatizing behaviors such as sexual abuse, premarital sex, and drug use. It is thus a limitation of the study, as findings may or may not represent the typical experiences of young migrants.

We consider that there is a continuum of psychosocial issues ranging from mild, emotional stress to severe mental health problems. This report is based on findings from interviews conducted with service recipients who were not receiving specific mental health care, but rather those who were receiving various forms of psychosocial support from Biruh Tesfa and Retrak. Although this study is about the mental health and psychosocial issues of migrant youth, it is likely that the issues expressed by the target population for this formative research fall toward the milder end of the range of the mental health/ psychosocial health continuum. 


\section{RESULTS}

Table 1 describes the composition of the study participants from both Retrak and Biruh Tesfa in terms of their gender, age, and role (client or service provider).

Table I. Description of study sample

\begin{tabular}{|c|c|c|}
\hline \multicolumn{2}{|c|}{ Service recipients } & Service providers \\
\hline Females & $\begin{array}{l}\mathrm{n}=15 \text { girls } \\
\text { age range }[15-2 \mid] \\
\text { mean age } 16.2 \mathrm{yrs}\end{array}$ & $\begin{array}{l}\text { Biruh Tesfa: } n=4 \text { females } \\
\text { OPRIFS: } n=2 \text { females } \\
\text { Retrak: } n=2 \text { females }\end{array}$ \\
\hline Males & $\begin{array}{l}\mathrm{n}=15 \text { boys } \\
\text { age range }[15-20] \\
\text { mean age } 16.3 \mathrm{yrs}\end{array}$ & Retrak: $\mathrm{n}=3$ males \\
\hline
\end{tabular}

The average age of both male and female clients was similar at 16 years. Most girls migrated from the Amhara region while the majority of boys came from Oromia (see Figure 2 for a map of Ethiopia's regions). The Oromia region is located south of Addis Ababa and is the most populous region in the country. The Amhara region is the second largest and most populous region in Ethiopia, situated north of Addis Ababa.

Figure 2. Map of Ethiopia regions

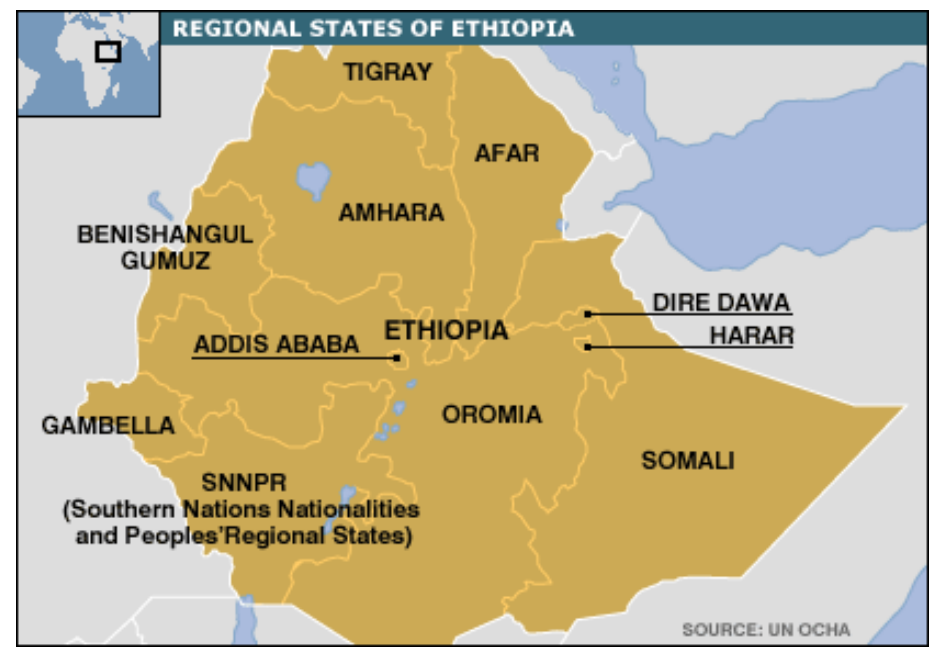

Source: United Nations (UN) Office for the Coordination of Humanitarian Affairs (OCHA)

While the challenges faced by adolescent migrant children are well documented, this formative needs assessment revealed several key findings that compromise the psychosocial well-being of Ethiopian adolescent migrants and may increase their vulnerability to HIV: i) sexual abuse among vulnerable 
migrant adolescents leads to psychological trauma; ii) social isolation, due to being overworked and separated from family and friends, compromises mental health status; iii) causes and outcomes of migration are consistent with existing literature on migrant youth; iv) service recipients and service providers are reporting inconsistencies in sexual behaviors and experiences; and v) service recipients demonstrate varying levels of knowledge and attitudes about HIV. We conclude the findings section with reported gaps in current service provision and suggestions for improvement.

\section{SEXUAL ABUSE AMONG VULNERABLE MIGRANT ADOLESCENTS LEADSTO PSYCHOLOGICALTRAUMA}

Many Biruh Tesfa service providers, and some beneficiaries, reported knowing girls who had experienced sexual abuse or rape. Service providers described many instances of rape and sexual abuse among their clients. (We should note, however, that when asked if they had experienced forced sexual intercourse, none of the girls interviewed reported being a victim of sexual abuse herself.)

One Biruh Tesfa mentor estimated that approximately half of all Biruh Tesfa girls are rape survivors or arranged marriage escapees. Several providers mentioned that many girls were raped by family members (i.e., father, brother, or uncle), rather than by strangers.

There was this girl whom I mentored, who got raped by her own uncle. Then he took her to another relative's house. After she came here to the project she used to cry bitterly when we give lectures about rape. No one knew her story. When we talked to her in private she told us that she was raped by her uncle and that she was sick ever since. We were very shocked so we rushed her to the hospital. She was just a child, a ten-year-old. She was negative for HIV but was still traumatized. Soon we discovered the address of the uncle and made the necessary calls to have him arrested. She is now a grade three student.

—Provider, Female, Biruh Tesfa

Of the 15 girls in the sample, one reported a personal experience of sexual abuse/harassment (attempted rape), and three girls reported knowing of sexual abuse among friends or acquaintances. Biruh Tesfa service providers acknowledged difficulties for girls to openly discuss accounts of traumatic sexual experiences due to the sensitive nature of and social embarrassment suffered as a result of the abuse.

Shisha [flavored smoking tobacco] is smoked in my aunt's house. There was this man who used to live there who came in one day and tried to rape me. I told my aunt about it and she warned him not to get near me again. He stopped doing it after she told him to stay away from me... no, they are not related. He is just someone who used to come there to smoke shisha. It was at night so they came there to spend the night. At that time I used to spend the night with the maid. We slept in the corner. I screamed when he came near me. My aunt came and asked me what is wrong and I told her. She then told him to stay away from me and to never come to the house again. He stopped coming to her home.

—Female, aged 15, Biruh Tesfa, from Oromia

I know this girl who lives around where I live... she was raped by a drunken person when there was no one at her house late at night. When she woke up in the morning her cloth was 
ruined with blood and after an examination at the health center they told her that she had HIV. Now I feel pity for the girl.

—Female, aged 15, Biruh Tesfa, from Oromia

She was our beneficiary. She lives with her mother and stepfather. Her mother stays outside working. When he stayed at home he tried such attempt twice, since he does not work. She kept quiet. We live close by and as a result she told me when going home after school. She was afraid that her mother may not trust her. She always stays outside until her mother comes. I informed her mother. ... I was following her up. Now she is with her grandmother attending class... People do not expose such a thing. In fear of social life they cover up such issues and they do not talk openly. The same father abused other children, out of the three people I told you. This is about one of the three cases I told you. They kept quiet what he did. We knew due to this child.

—Provider, Female, Biruh Tesfa

These findings suggest that girls may be withholding some sensitive information related to sexual abuse for fear of being stigmatized. Indeed, Biruh Tesfa mentors and OPRIFS counselors mentioned that often girls would come and see them on several different occasions before admitting the true nature of their troubles.

One provider reported a case of a girl who appeared to be mentally unstable and was being sexually abused.

There was this girl who had a mental problem. Many people were using her due to this. We helped her start using contraceptives. She got pregnant and her relatives had no money. ... She is 15 years old... [Was it sexual abuse?] She does not know as such they cheat her with small things... She thinks everything is good. She does not differentiate what is right and wrong... she does not know. We do not know the person [from whom she got pregnant].

—Provider, Female, Biruh Tesfa

This case suggests a vicious cycle between having mental illness and being sexually abused, and hence the potential for increased HIV vulnerability, especially considering that such sexual abuse is not likely to involve condom use.

\section{“Bed renting” exposes girls to sexually exploitative situational circumstances}

Many migrant girls are put at risk for sexual abuse by being forced into a common practice known as "bed renting". This is a routine or nightly process in which a girl is required by her employer to frequent areas of the city in search of a tenant to rent a room or vacant bed in the same house in which she also works and lives, so that the employer can earn extra money. Bed renting places undue risks upon girls by having to solicit strangers, mainly men. Most girls in the study sample worked as domestic house help or rented out beds, or both. Those whose jobs included being involved in bed renting expressed fears of sleeping under the same roof as men with potentially malicious intentions.

... A lot of people rent beds to spend the night. The children sleep in the same room as the 
customers. You can imagine the kinds of things that can go on there... [What are the factors responsible for such incidents?] Alcoholic drinks are a major factor. Most customers ... are drunks. Since they [the girls] share the same room with the renters, the chances of getting raped are high.

—Provider, Female, Biruh Tesfa

Due to financial constraints, one Biruh Tesfa participant was living in a bed renting house in which she and her mother both were living together and responsible for soliciting bed renters for the house owners. One service provider claimed that families who migrate or send their daughters to Addis Ababa know and even implicitly accept that rape is a highly likely consequence of being responsible for renting out beds, highlighting an urgent need to address the seemingly well understood and accepted risks of this line of work.

It really upsets me when I see people actually sleeping above me-but since our livelihood is solemnly based on the rent, we have to do it.... There are many things that can go wrong... They might start a fight, some come in drunk and they might die there. We are really worried about these things. But since we do not have another source of income, we have to do it.... If there is no one home some might try to rape you, just because we rent [out] a bed some get the wrong idea and want more than just the bed.... They want you to be a girlfriend with them. After you refuse they look for opportunities to attack you....

—Female, aged 17, Biruh Tesfa, from Amhara

\section{Boys also experience sexual abuse and increased HIVISTI risk}

Many boys relayed stories of friends or other boys who had suffered sexual abuse. Retrak service providers acknowledged that it is particularly difficult for boys to openly talk about and admit to being victims of sexual abuse due to the cultural stigma attached to homosexuality, suggesting that such incidents are likely underreported in this study and in general.

There are those that do it out of desire and those doing it against their will - those that have been raped by men. Though not many, there are some everywhere... against their will means man to man, with desire means man to woman. They go to the prostitutes. They are raped by the same sex. This is hard to accept from a behavioral, moral, or religious point of view. But the problem exists.

—Provider, Female, Retrak

One day I was carrying luggage for a man who is big, he is as big as my father, and he asked me to show him a rest place to sleep and he kissed me. I was surprised and langhed. I was looking at him with astonishment. I used to sleep on the street back then and he gave me ten birr [US\$.55]. He asked me are you ok with the amount of money? I said to him God bless you. He added 10birr more and I said thank you. He said to me don't you laugh. I said saying thank you is more than laughing. He asked me where I sleep. I told him that I sleep on the street. He told me that I can sleep there [with him] and he kissed me. Then I promised to go back and sleep but did not go there. I knew that he was leading me to sexual acts.

-Male, aged 17, Retrak, from Southern National Nationalities 
There is a child when I was in Merkato [bus station area in Addis]... [Was he part of your group?] No he was not. He came to us to let him sleep with us. He was big... he was permitted to sleep. Then he sexually abused a child. The child told the group in the morning. Then they took him to the police. He was put in prison. [Do you know the child who was sexually abused?] Yes I know him [What did he face after that?] He was not able to walk properly. He was hardly walking. He went to this foreigner for health services.

—Male, aged 16, Retrak, from Southern National Nationalities

As noted with the girls, none of the boys in the study reported personal experiences with sexual abuse.

\section{SOCIAL ISOLATION COMPROMISES MENTAL HEALTH STATUS OF MARGINALIZED MIGRANTYOUTH}

\section{Girls lack social interaction due to demanding work schedules and restricted mobility}

Nearly all of the Biruh Tesfa service providers agreed that their service recipients experience a high degree of restricted mobility and limited opportunities to socialize outside of the program since they are typically closely monitored by their employers. While some girls reported engaging in social activities such as playing suzy (jump rope) and tag, limited exposure to and time for socializing was reported as a major constraint for most of the girls in the study. However, when asked what they prefer to do in their spare time, many girls responded with individual chores such as cooking, instead of citing more recreational, group activities suited for young girls. Thus, it appears that due to having an ongoing restrictive lifestyle, these girls have limited options for spending their free time if it were provided to them, whereby making them even more vulnerable to peers or other ill-intentioned people. In addition to the lack of personal freedom and mobility, other reasons reported for not socializing included fear of being taken advantage of by strangers, fear of disobeying authorities, and disapproval by employers.

I never really communicate with anyone. ... We do have neighbors but we are not that close. ... I didn't get the chance to get close to anyone so I have no friends. ... Ever since I arrived at this school I had the chance to play with the others. But I didn't make any friends. ... They are all adults. And besides, I have never been outside of the house. ... I just sit in the house.

—Female, aged 15, Biruh Tesfa, from Regional 9

This lack of social interactions has left some girls with Biruh Tesfa mentors as their only source of socializing. One provider mentioned that girls will sometimes make appointments to meet with her not because they have a particular problem or health concern but simply because other girls are doing the same and they don't want to be excluded from such conversations. Some girls exposed to extreme forms of social isolation reported reaching a level of acceptance where they no longer questioned or strived to change their circumstances. Two OPRIFS providers made explicit mention of girls suffering from serious psychological trauma, who had already been referred by Biruh Tesfa to OPRIFS for further evaluation and counseling. 
In most cases, when they face challenges you can see that they isolate themselves and sit separately. For instance, you can see one of them crying very, very hard in one of the corners, mentioning her mother's name.

—Provider, Female, OPRIFS

Interpersonal communication among girls was also limited due to fear of negative peer pressure to disobey authorities, though some girls did report close friendships in which intimate topics such as coming of age and instances of abuse were discussed amongst themselves.

\section{Social isolation among boys can lead to physically violent and aggressive tendencies}

Social isolation in the form of exclusion from the rest of the community at large was evidenced among the boys. While reported pastimes included watching movies and playing games such as football or joteni (foosball) with other boys, most preferred spending time with only a few close friends whom they could trust. One provider claimed that the reason why boys don't have many friends outside of Retrak or their place of employment is mistrust by the outside community, which often views street boys as thieves or trouble makers.

The habit of entertainment and social life of the boys mainly revolves around one another and does not include external society... they have little or no social life with the society.

-Provider, Male, Retrak

Similar to the girls, several boys, including those who said they did not have any or close friends, reported sharing their grievances with Retrak counselors in order to seek advice. While a few boys reported feeling a level of closeness and kinship with their roommates and other Retrak boys, most boys did not report having close friends making it difficult to fully understand the extent and complex nature of their limited interpersonal relationships. Reasons for lack of close friends included fear of peer pressure from other boys to engage in risky or illegal activities and fear of being taken advantage of by other street boys.

Wherever I think of something I blame myself. ... I used to say I was not supposed to be born. [Were there other things the children did to you?] I did not get along with any one so I usually keep quiet.

\section{-Male, aged 15, Retrak, from Southern National Nationalities}

Boys seemed to use physical aggression as a coping mechanism to deal with their social isolation and as a means of indirect communication to authority figures. Boys often reported feeling angry and lashing out at people who frustrated them. Main instigators for such behavior include invasion of personal space/ privacy, being yelled at or reprimanded by authority figures, or when someone betrayed their trust. This aggression and inability to tolerate ridicule was often heightened when a stranger or authority figure disrespected a boy, adding to the boy's dissatisfaction with his current situation.

I hit people. I have patience but sometimes I might hit people. I have patience but sometimes I might hit a child. If it is beyond my capacity I tell the staff in the organization.

—Male, aged 15, Retrak 
More than half of the boys reported some experience with or exposure to physical violence. Police and official baggage carriers inside the bus station often chase away and even physically abuse street boys attempting to offer services to passengers without a valid license. Repeated verbal and physical abuses engender feelings of inferiority, which often result in outward displays of physical aggression. Boys mentioned being victims of physical violence from street gangs, family members, and law enforcement officials. Prior to joining Retrak, several boys endured physical abuse while living on the street as well as at home by their family members.

A police physically abused me when I stayed on the street. My mom was concerned that I was on the street. I did that to show her that I want her to live with my father. She told the police that I was difficult to handle. My character was also by then difficult and I got punished physically by police. I insulted the police and that made them beat me more.

-Male, aged 17, Retrak, from Southern National Nationalities

\section{CAUSES AND OUTCOMES OF RURALTO URBAN YOUTH MIGRATION ARE CONSISTENTWITH EXISTING LITERATURE}

In order to contextualize the risks faced by adolescent youth in Addis Ababa it is useful to examine the reasons for migration in the first place. The interviews shed light on the type of family and home life situations these youth experienced prior to arriving in Addis Ababa and provide a useful base with which to compare their current living situation.

Most respondents reported traveling to Addis Ababa with a relative and/or to visit/stay with a relative. The reasons most youth cited for migrating were consistent with the current literature and included:

1. Desires to be further educated (12 service recipients);

2. Escape an abusive or conflicted household, including escaping an unwanted marriage (16 service recipients), or;

3. To earn money, often times after death or divorce of one or a remaining parent (8 service recipients).

Many adolescents also cited frustration with authority figures and anticipation of a free life in Addis Ababa as reasons for migrating.

Boys reported migrating to Addis Ababa mainly to seek further education, escape family conflict at home, or to earn money for themselves or siblings often following the death of a parent, and then feeling happy due to freedom from authority that comes with living on the street.

I was supposed to work in the shop. I had less time to study. At some point my grandfather slapped me on the face asking why I did not keep the shop. .... I hit him back on his face. He took his gun and wanted to kill me. ... He told me to leave the house. I went to the streets. My grandmother used to help me hide from him. She used to pay for my house rent and food allowance. I lived like that for a while and then came here.

—Male, aged 16, Retrak, from Oromia 
Several girls reported that their parents/guardians were denying them educational opportunities and that they left their homes to escape unwanted marriage.

I grew up with my cousin in my grandmother's house. But she used to send him to school while she kept me in the house. She believed that a girl should stay at home and wait for a husband and that she should never go to school. So I secretly consulted my cousin and he helped me to come here to my mother's uncle's place. He lives here in Addis Ababa.

—Female, aged 17, Biruh Tesfa, from Amhara

However, many adolescents faced similar frustrations with other family members or authority figures after leaving their homes and coming to Addis Ababa. A number of girls reported explicitly disliking their current living environment in Addis Ababa. The majority of the reasons for this include not being appreciated for work done, being berated or insulted for work not completed properly, and experiencing a general lack of empathy from their employer or others living in the house. Other reasons cited for dissatisfaction in the home included being overworked, under paid or not paid at all, or being denied educational opportunities by the head of the household, which in most cases was a relative such as an aunt or uncle.

Several boys and girls reported regretting coming to Addis Ababa and wanting to return to their families. Many girls cited personality conflicts with their employers or extended family members and unrealized promises for payment for working.

Migrant boys in the sample had reached higher levels of education than migrant girls. Girls appeared motivated to resume their studies as they felt it was the only way to improve their current living situation, but nearly all cited lack of financial resources as the reason for discontinuing their education or not being able to resume classes. Some participants noted that they moved to Addis Ababa to seek better financial opportunities or to earn a living after the death of a parent, implying a financially insecure home life. As most girls were engaged during the day completing their household chores, night school was often the most realistic option to continue their schooling in Addis Ababa, though it posed additional dangers related to venturing out late in the evening hours.

Payments for girls working as domestic workers were reported as irregular but more often missing altogether. Girls working for family members usually reported not being paid, whereas girls working for non-family members were given a salary. Some employers claimed that the food, shelter, and clothing they provide counts as the girl's salary or withheld their salaries and claimed that they sent the money back home to the girls' parents. Often girls did not explicitly ask for a salary as they felt that their extended family was doing their parents a favor by relieving them of their caretaking duties of looking after the girl. Most girls who did earn an income saved their money and sent some of it back home to family.

She pays the other maids 300birr each [US\$16]. But there is no salary for me. She is the one who buys me clothes, shoes, and hair lotions... They ask me if I want shoes or clothes but they never talk to me about money. The other maids are getting paid. I work like a maid but they never talk to me about money... I'm afraid to ask because they are relatives. I know that if I was hired elsewhere I would get paid just like other maids.

-Female, aged 15, Biruh Tesfa, from Oromia 
Boys' wages were based on how often they work, as many are employed as temporary workers carrying bags or injera (Ethiopian gram meal), tailoring clothes, shining shoes, selling goods by the roadside, or other vocational training jobs, while some survived on begging. Some boys reported earning up to as much as 100 birr a day (US\$5.40) by engaging in a variety of odd jobs. Several boys reported saving their earnings at Retrak for personal recreational use or to share with a few select friends in need. Unlike the girls, none of the boys reported sending their saved money back home to assist family members. Girls and boys both expressed concern about not being able to return home without having economic gains to show for their time spent in Addis Ababa.

Whenever someone goes back to visit family in the country side they always wonder what hel she brought for them. They don't care about the person so I can't go there empty handed. They are struggling to make it on their own. It is best for me to try to survive here than going there and be a burden to them. I might go there if I have something to give them. I can't go empty handed.

—Male, aged 20, Retrak, from Oromia

\section{LIKELY UNDER REPORTING OF SEXUAL EXPERIENCES}

Overall reports of sexual engagement among both boys and girls appeared low. Boys were more likely to report engaging in consensual sexual intercourse than girls. Three boys reported that they had previously been sexually active while the remaining twelve boys claimed never to have had sex. No girls reported ever having been sexually active; nine girls definitively said that they had never had sex, while six did not specify. This is in contrast to the reports by the providers, most of whom indicated that a good number of their service recipients had experienced sexual intercourse through coercion or sexual abuse for both boys and girls and, in the case of boys, also through sex with sex workers.

The low reported levels of sexual activity could be due to the fact that most boys and girls are in fact not having sexual relations or it could be due to social desirability norms, which could be based on the attitudes of their providers toward sexuality of young people in general. Alternatively, those who had experienced sex through coercion or sexual abuse could have chosen not to report it due to the psychological trauma or the fear of stigma associated with such sexual experience as opposed to sexual intercourse within a relationship. Several girls even reported that they felt too young and unready to be in a relationship.

I am only 16 years old and that is early for a relationship. So I do not want it. I just want to learn. ... If I get married my mind will be on it ... so I won't be able to learn in such a situation.

—Female, aged 16, Biruh Tesfa, from Amhara

Indeed, some service providers expressed the belief that because some girls had experienced sexual abuse or had been in abusive marriages they were not likely to desire romantic relations. One Biruh Tesfa service provider commented that girls working as maids are not in a position to engage in amorous relationships.

Since they live as maids things are not suitable to start this kind of life. ... As far as we know, they are not [romantically] involved... some of them are divorcees, they got divorced when they came here.

—Provider, Female, Biruh Tesfa 
In general, boys seemed to be well informed about the consequences of risky behaviors and how these behaviors, such as drug and alcohol abuse, can lead to risky sex practices, thus increasing their HIV vulnerability. A few boys reported previous experience with drinking alcohol and/or chewing mild stimulant substances such as chat. No boys in the sample admitted to currently engaging in these risk behaviors and cited the influence of Retrak in their stopping or avoiding these behaviors altogether and also making them want to disassociate with other boys who drink alcohol or chew chat.

Boys face significant peer pressure to engage in risky behaviors, such as unprotected sex. Of concern are the risky sexual behaviors that boys willingly engage in. Several Retrak participants talked about friends who visit sex workers. Although some of the boys in the sample admitted that they, too, were tempted to visit sex workers none reported ever having personally paid for sex, sometimes citing the influence of Retrak's HIV awareness/life skills classes as having discouraged them. Service providers working among vulnerable boys reported that many male service recipients are known to be paying for sex and/or going to see pornographic movies at video houses, both of which are explicitly addressed and discouraged through the Retrak Life Skills program. This is an issue of great concern because Retrak service providers maintain that once boys begin watching pornographic movies they quickly become "addicted" leading them to take greater sexual risks.

They go to movie houses for relaxation purposes. There they watch unhealthy movies [pornography] and spend their time smoking and chewing [chat]. There are movie houses around our area. They pay a very small amount, such as 1birr [\$.05USD] and can watch [movies] the whole day.

—Provider, Male, Retrak

Comments from one of the boys in the sample indicated that some boys have unsafe sex as a result of consuming alcohol.

[Those who take alcohol, chat] cigarettes, and glue will they be exposed to unsafe sex? Do they show a behavior of having unsafe sex?] Yes, most go for it - they don't think of using condom. They don't think what will happen to them.

—Male, aged 15, Retrak, from Amhara

The above is corroborated by service providers who fear for the risks that the boys take, such as engaging in unprotected sex when they visit sex workers, even though during life skills classes they are taught about safe sex practices and how to avoid HIV risks.

\section{VARYING LEVELS OF KNOWLEDGE AND ATTITUDES ABOUT HIV}

Some service recipients demonstrated a remarkably sophisticated and knowledgeable grasp of the facts of HIV transmission, as evidenced by this 17-year-old Biruh Tesfa participant.

I know HIV is harmful and that it is not curable. I also know that it can be transmitted through unprotected sex, from mother to child during breast feeding and through blood 
transfusion. ... Care should be taken while transfusing blood. The blood must first be tested for HIV before it is donated. And those who are romantically involved should abstain from sex until they get married. And when they do decide to get married, they should first get tested for HIV.

—Female, aged 17, Biruh Tesfa, from Amhara

However, further probing revealed a resistive attitude toward condoms which could hinder the ability to translate accurate knowledge about HIV into action with regard to preventive behavior. This is consistent with the theory of planned behavior in which one's behavior is affected by one's attitudes, perceived behavioral norms, and intention toward finally taking action (Azjen 1991), which in this case is practicing safe sex.

I have learned about HIV here in this school. I know it is transmitted when people don't use condom. Since I haven't concerned myself about it, I don't know what a condom is. I don't see the purpose in asking.

—Female, aged 15, Biruh Tesfa, from Amhara

On the other hand some young people displayed knowledge gaps in the area of HIV transmission. Indeed both boys and girls seemed to emphasize greater HIV transmission risks by sharp objects such as needles and blades prior to mentioning sexual intercourse as a risk factor, and often after additional probing by the interviewer.

[Do you want to get tested for HIV again?] Yes. [Why?] To know whether I am free or not. [Do you fear? Did you do something that makes you fear?] I don't have anything to fear, whether I do the test or not... [Do you protect yourself?] Yes. [For instance, what do you do?] I don't brush with other's toothbrush.

-Male, aged 15, Retrak, from Oromia

[So you want to be tested for HIV because you don't think that you have taken the necessary precautionary steps?] Yes [Ok, you said that the risks of things like a razor blade can cut you, right?] Yeah [Just that way? Don't you think there are other ways?] Just that way; not in any other way. There is nothing that I don't know that I did [to put me at risk]. [How, how about sex] ... I am free from that [It could be unintentional] Never.

—Male, aged 15, Retrak, from Oromia

Despite the low reported levels of sexual activity, many young people said that they had been tested for HIV, some multiple times, in order to confirm that they were not at risk. One girl who said that she had never been sexually active reported that she had been tested for HIV when she went to see the doctor for a stomachache. A service provider confirmed that requests for HIV tests are often initiated by girls when they visit a doctor for other reasons including illness, physical check-up, obtaining a visa to work abroad, etc., rather than provided directly by a referral from Biruh Tesfa. Similarly, a boy who said that he had never been sexually active described how he had received an HIV test through a voluntary campaign at his school. 


\section{REPORTED GAPS IN CURRENT SERVICE PROVISION AND SUGGESTIONS FOR IMPROVEMENT}

Respondents indicated that in addition to offering basic education, life skills training, mentoring, and referral services to counselors, psychologists, and medical staff as required, Biruh Tesfa mentors also act as advocates for the girls, lobbying with families and employers to allow their girls to join the program and engage in much needed recreational and socialization time.

We sometimes interfere and negotiate with their employers to give them some of their money. Then we make sure that they save their money in order to do something for themselves. Some employers refuse to let their house maids participate in the project [Biruh Tesfa] because if the girl attended this education they would know their rights, know about financial savings.... They don't want to see change in their maids so they take them out and send them home.

-Provider, Female, Biruh Tesfa

Data also showed that through the use of counselors, nurses, teachers, and psychologists, Retrak reaches out to street boys to offer educational and counseling support and resources in the form of life-skills programs and promotion of condoms. Having identified factors that lead to risky sexual behavior, Retrak's counseling sessions have focused on reducing these risk factors, including drug and alcohol abuse and viewing adult films.

Since they are exposed to such things, we teach them about it. As I told you before, they go to the cinemas if business is slow. Sometimes they watch pornographic films. They sometimes get aroused and go to the prostitutes. We give special attention to those that are 13, 14, and 15 and tell them about it. In the Life Skills Program we tell them that they should always use condoms and they should not even watch pornographic films. They can watch a bunch of movies for hours with just 1birr [\$.05USD]. There are video houses that offer such services around here. They say that they have nowhere else to go and kill time. So they go to these houses, get aroused, and do awful things. Every boy here knows about it.

—Provider, Female, Retrak

However, the following service gaps were also noted by providers.

1. The problem of not being able to express their feelings remains an ongoing challenge for some young people;

2. Developing and nurturing a trusting relationship takes a considerable amount of time and probing during counseling sessions;

3. Many boys do not open up and share their experiences immediately upon arrival to the Retrak program;

4. Girls often reported using silence as a coping mechanism to deal with authoritative employers or family members, making it difficult for Biruh Tesfa providers to assess and address the root cause of their problem.

The following quote shows one beneficiary's response when asked how she deals with life's problems/ challenges, suggesting the client's need and perhaps desire to discuss deeper, underlying emotional and psychosocial issues. 
I just look at my life and let it [challenges] go away. I believe that this will happen anytime in my life. This is part of life. Wherever I go, whatever people do to me, even beat me, I just keep quiet and let it go silently.

—Female, aged 21, Biruh Tesfa, from Southern National Nationalities

In response to the hardships migrant youth face, many respondents, adolescents and providers alike, suggested that adolescents need to work harder to resolve family issues and not leave their homes in the first place. Some providers suggested that children often migrate due to a sense of arrogance or apathy in dealing with their problems at home, that if resolved could prevent further disappointment and challenges upon migration. Enforcing adequate justice for perpetrators of violence against children and greater collaboration among government and civil society was also suggested by several service recipients and providers for curbing current and preventing future child abuse.

We need to raise awareness together with government. You said girls are exposed but currently boys are also becoming victim to such abuse. They do this purposely to abuse the boys. They plan and design ways to sexually abuse males. The government has to follow such abusers legally. There are children with us who were abused but punishing the abuser with legal measures is difficult. If they cough [give a bribe] they will be released within a day from prison. The temptation is high and it is increasing enormously from time to time.

—Provider, Female, Retrak

We should eliminate the problem from the root. When we ask why they are on the streets in the first place they give you different kinds of reasons. So it is better if an assessment is made based on these reasons and preventive measures are taken along with the government so that the children don't go out on the streets in the first place... For instance, if links are made with another organization which follows up a child after we have reunited him with his families, an organization that handles the family. If the family needs economic empowerment, the organization will take the responsibility to provide such support. If the boy got out of the house because of poverty, a link should be formed to alleviate the problem. We should have a network with the police. Some flee from their homes because of abuse. In order to help the boy deal with his problems there should be government support. The effort made by NGOs alone is like trying to clap with one hand.

—Provider, Female, Retrak

We currently do prevention work at the community level. There are what we call awareness raising and community-based child protection units. We have committees which join them together and do the job. In that case the most important element is the awareness raising program. The awareness raising focuses on child trafficking, child abuse, and other similar issues. Particularly if the community is aware they can prevent it themselves. Thus, if we scale up/duplicate these systems and programs in those places well — we might get away with the problem. Even if it may not kill it, it would minimize the problem to a higher degree.

—Provider, Female, OPRIFS 
Some providers specifically mentioned how strengthened counseling services would greatly benefit clients who have been victims of abuse and severe psychological trauma for whom traditional modes of counseling have not proved beneficial.

It's when you change your behavior that you can bring change to any aspect of your life. The other is secondary; the main point is in the counseling. If you shape his behavior he will learn to tolerate and cope with life on the streets. Behavior is a determining factor for any aspect of life. ... Its best if the play therapy is strengthened. There should be capacity building of social workers so that more effort is made towards counseling addicts. There are some children who come to us after they are sexually abused. We give them a special kind of counseling... Sexually abused children have different personalities. We only come to understand their problems at the end. They become naughty and display different behaviors. So there should be capacity building in the therapy area. Since there will be more addicted children, we should work on how to handle them.

—Provider, Female, Retrak 


\section{DISCUSSION}

Gender norms and attitudes can impact emotional health and well-being (UN 2003). Such norms may affect whether and to whom boys and girls feel they can rely on for emotional and social support. Gender norms also affect how mental and psychosocial health issues are experienced by boys and girls (UN 2003; International HIV/AIDS Alliance 2003). Both boys and girls can feel restricted by such attitudes and expectations, precluding them from being able to make healthy lifestyle choices.

Our study has shown gender differences in the problem of social isolation among female and male migrant youth. Biruh Tesfa providers in the study noted that many of their beneficiaries are quiet and often need to be probed several times to speak up during class, a behavior which may inherently be more culturally appropriate for girls in Ethiopian society. That said, many girls expressed desire for freedom that they are not afforded in their current working conditions but often feared to talk with someone who may know their employers. Girls also experienced emotional stress due to poor working conditions, and abuse by employers. It is also widely accepted that poverty is one of the main barriers to girls' access to education and financial growth opportunities worldwide. Temin et al. also found that the anxiety of separation from family and social networks and poverty can impact migrant girls' mental health well-being (Temin et al. 2013). Temin and colleagues found that many migrant girls had poor social networks, which can limit their ability to access information and routine services. They also observed a gender difference in social isolation, where 40 percent of recent migrant girls reported having no friends versus 13 percent of migrant boys (Temin et al. 2013). While girls in our study tended to channel their emotions inwards, boys had an outward display of emotions, often resulting in physical violence. Boys also reported experiencing emotional stresses due to various causes such as being bullied or criticized and often expressed their frustrations through aggressive behavior.

Findings on sexual abuse from our study have been echoed in literature among adolescent migrants in Ethiopia. Other researchers have found that child sexual abuse (CSA), especially among girls, is increasing in Addis Ababa and that there is a great need to strengthen prevention efforts and increase awareness of the magnitude of the problem. Young migrants have been reported to be at high risk of sexual abuse, and additional social awareness and protections have been called for (Melesse and Kassie 2005). Melesse and Kassie also found that only 18 percent of children who had been sexually abused in Addis Ababa received psychological follow-up visits, further demonstrating the need for immediate and appropriate psychosocial care for sexually abused youth. However, girls may not access these services if they remain inhibited in reporting sexual abuse, as has been shown by our study. Other studies on female sexual abuse in Ethiopia (Lakew 2001; Molla et al. 2000) agree that the reason girls often delay reporting instances of sexual abuse is fear of stigma from their family and society or fear of their offender or the authorities. Similar deterrents for delayed or absent reporting of sexual abuse have been noted among boys as well, (Moore 2007; Lakew 2001) especially among those who have been victims of same sex rape. In our study providers and girls reported several instances of sexual abuse among girls who express their grief through crying or reporting their feelings to their counselors, often after several probing attempts. These emotions should be addressed by professionals who are trained to handle issues regarding adolescent psychosocial and mental health well-being. 
While research regarding CSA among boys is not as widely available as it is for girls, findings from our study support the existing literature, which suggests that this is a growing problem (Tadele 2009). Although none of the boys in our study sample reported personal experiences with sexual abuse, a few boys and service providers reported knowledge of other boys who had experienced sexual abuse. These findings highlight a concerning trend that boys also experience sexual abuse and need to be provided urgent and immediate counseling and care. As noted earlier, due to the small sample size it is not assumed that these findings can be necessarily generalized to the larger overall population, making it difficult to assess whether or not male sexual abuse is being under reported in this study, as suggested by other scholars (Tadele 2009).

It is also important to consider gender in the context of HIV vulnerability. Gender norms largely influence whether girls or boys have access to information they need to promote healthy sexual behavior, whether they can act on that information (ICAD 2006), and whether they will be able to access essential testing and counseling services. The findings from our study evidenced several gender differences in vulnerability to HIV and other risk scenarios. Boys seem to use their freedom to pursue adventure and take risks such as using their earnings to watch pornographic movies with their peers and seeking out sex workers. Girls are put in positions where they are at increased risk of being sexually abused by being obliged by their employers to solicit men to rent out sleeping beds in their households.

Many service providers from both Biruh Tesfa and Retrak noted that service recipients often had to be probed several times before they felt comfortable sharing their personal problems and associated emotions. This is not an uncommon phenomenon for migrant children, many of whom have experienced grief, anger, or hurt from unfortunate family circumstances, such as parental divorce, death of a parent, denial of basic rights, forced marriage, or physical or sexual abuse. Upon migrating, these emotions can be heightened without the appropriate psychosocial support and positive coping mechanisms, and are likely compounded for youth recovering from the trauma of suffering physical or sexual violence. Long term consequences of abuse early in life have been well documented and can increase risk behaviors, such as drug and alcohol abuse, as well as likelihood of mental health problems (International HIV/AIDS Alliance 2003). The UN Convention on the Rights of the Child and the African charter on the Rights of the Child suggest several guiding principles for delivering psychosocial support to orphans and vulnerable children. These include intervening early-on to prevent further detriment to their psychosocial status, promoting individual sense of identity, providing safe and ample opportunities for play and recreation, as well as involving the community in providing psychosocial support (International HIV/AIDS Alliance 2003). Several of these guidelines were considered in the development of the psychosocial study intervention for this target population, as discussed further below. 


\section{EVIDENCE INFORMING INTERVENTION}

This study was designed to examine the psychosocial and mental health problems of young migrant adolescents in Addis Ababa, Ethiopia in order to recommend a targeted intervention to address these problems. Six key findings were discovered regarding high risk conditions that adolescent migrants in Addis Ababa are exposed to that specifically compromise their psychosocial well-being and increase their vulnerability to HIV. First, sexual abuse among vulnerable migrant adolescents leads to psychological trauma; second, social isolation compromises mental health status. Third, causes and outcomes of rural to urban adolescent migration were consistent with previous findings in the literature which have shown that children migrate from rural areas to escape poverty, abuse, and difficult family relations and often end up facing similar challenges in the urban areas. Fourth, service recipients appear to be reporting low levels of sexual activity when compared to the perspectives of their service providers, and lastly, service recipients report varying levels of knowledge and attitudes about HIV. The study has also highlighted gaps in current service provision and suggestions for addressing them.

\section{STUDY-SPECIFIC RECOMMENDATIONS FOR A TARGETED PSYCHOSOCIAL INTERVENTION}

An expert committee comprising a psychologist, a psychometrician, and a psychiatrist from Ethiopian universities; service managers from Retrak and Biruh Tesfa; and the Population Council study team met to discuss preliminary findings from this study and to recommend targeted interventions to address the main psychosocial vulnerabilities and risk factors identified, with a view to provide psychosocial support in general, and to reduce their vulnerability to HIV specifically. Table 2 describes the psychosocial interventions and their basis in study findings. In addition, the selection of interventions was influenced by feasibility of implementation by Biruh Tesfa and Retrak in Addis Ababa within available resources. It should be noted that the proposed intervention modalities were suggested by service providers from both Biruh Tesfa and Retrak. 
Table 2. Recommended psychosocial interventions based on study findings

Finding

Young, migrant adolescents face specific situations of vulnerability, including sexual and physical abuse in their work and home life settings. These compromising situations differ among girls and boys and cause psychological trauma that can lead to greater risk taking behaviors.
Intervention

Individual counseling:The expert committee deemed it necessary to provide both boys and girls with one to one counseling to enable the youth to raise and discuss psychological issues with his/her counselor. Counselors will employ a client-driven approach to target the needs identified by the specific boy or girl. Counselors will be trained to be sensitive to gender norms, attitudes, and expectations. To ensure that female clients feel comfortable opening up, all girls will be provided with a female counselor.*

Due to the severe social isolation faced by migrant adolescents many service recipients may not be opening up to discuss sensitive, personal issues, making it difficult for the service providers to provide comprehensive support.

The study found that the community at large does not have a good understanding of the issues and needs of the vulnerable children served by Biruh Tesfa and Retrak, nor do adolescents feel connected to the community at large. This lack of awareness may be contributing to a non-supportive or abusive environment and stigma resulting in fear and lack of trust in community members by the children served by Biruh Tesfa and Retrak. These barriers can prevent children from making use of available community resources that can help them generate income and address poverty.
Group counseling and art therapies:These group activities will be based on gender-sensitive and culturally acceptable activities of art therapy $y^{\#}$ music, dance, and drama, to encourage greater socialization and alternative modalities for youth to "open-up" and better express deeply seated thoughts and feelings. The dramas will depict scenarios that are realistic to lives of migrant adolescents. For boys this will include peer pressure and risk taking behaviors such as smoking/drinking alcohol. For girls this will include typical domestic house help scenarios and relationship dynamics between the employee and her employer**

Community engagement events: The study intervention will include events to raise community awareness about this vulnerable group of migrant children, eradicate harmful misconceptions, and help better integrate them into the society. The target audience for these events will be gatekeepers and decision makers who can affect the ability of these youth to make and implement decisions to improve their lives. For boys this will include administrative officials, employers, legal officers, and local community members living and working near the Retrak center; for girls this will primarily include their employers and other community members.

*Both individual and group counseling activities will be provided above and beyond the current counseling and social support services provided by both Biruh Tesfa and Retrak. These intervention mediated counseling sessions will be administered by certified counselors who will have been trained by the study staff and informed of the results of this study to help orient them to the types of psychosocial problems facing this vulnerable population. Outcomes of both individual and group counseling will be recorded in the form of counseling record books.

\#Lusebrink,V. 2004. "Art therapy and the brain:An attempt to understand the underlying processes of art expression in therapy," Art Therapy: Journal of the American Art Therapy Association 2 I (3): I 25-I 35.

As noted earlier, gender norms and vulnerabilities were taken into account when developing this set of interventions aimed at supporting psychosocial health among the target group of boys and girls. Results from a 2010 Stepping Stones study in Uganda showed that giving girls a safe space to communicate issues of social well-being empowered them to identify and discuss important topics such as sexual abuse, violence, and social isolation (Bollinger 2010). In particular, this specific need for girls to feel 
safe in a supportive environment was taken into account when developing the individual and group counseling components of the study intervention to ensure that girls' feelings and experiences are valued and understood by a cadre of trained professional counselors. Similarly a participatory experience and sharing process can allow different members of the community to learn about how others may affect or be affected by their actions (Implementing Stepping Stones 2007). This concept was a main impetus in developing the Community Awareness Raising Days component of the intervention to allow youth to showcase their talents and desires to a larger group of constituents. A participatory approach will also be employed in delivering the individual and group counseling sessions, as existing counselors from Retrak and OPRIFS will be trained to be gender sensitive and ensure each session is guided by the different needs of boys and girls respectively. This continuity of counseling staff will hopefully also facilitate greater trust resulting in more openness from the client and increased disclosure of sensitive information.

The expert committee also recommended that a comprehensive counseling training manual be developed to instruct counselors on how to deliver these counseling interventions. It is hoped that the results from this formative study as well as those from the forthcoming intervention study will add to the body of literature on marginalized adolescents and street children in Ethiopia and methods of caring for them.

The psychometric screening tool, adapted/developed during the second phase of this study, will also be administered to the study population to determine the severity of issues experienced by a given youth. This will, in turn, determine what types of interventions are most appropriate for the individuals. In order to measure the impact of the interventions developed in response to findings from the formative phase of the study, baseline and endline assessments will be conducted among the same population before and after the intervention in the third phase of the study.

\section{BROADER RECOMMENDATIONS FOR GOVERNMENT AND STAKEHOLDERS}

There are a number of structural factors, beyond the scope of this project, that contribute to the problem of migration, compromised mental health mental status, and HIV vulnerability among young people. In order to ensure a long-term solution to the issues highlighted in this report it is important that relevant stakeholders undertake further research and actions in order to understand and address the root causes of these problems. To highlight the importance of these factors, the team compiled a list of suggested action items for future action or research. The following recommendations are presented for consideration in order to provide a comprehensive response to the problems of vulnerable migrant children in Addis Ababa.

- Families and communities should be educated about the challenges migrant youth face in Addis Ababa and how they differ drastically from initial expectations. These sessions should also focus on increasing awareness of psychosocial development, which may help reduce household conflict and psychopathology related to poor adjustment, and increase community-level understanding of adolescent psychology (WHO 2003). As Biruh Tesfa in particular operates in several less urban parts of the country outside of Addis Ababa, these centers may consider offering education/information sessions to local employers, families, and communities.

- Family conflicts appear to be a key impetus for children leaving their homes to migrate to the city. Families, including parents and children, would greatly benefit from receiving training in parenting and conflict resolution skills. Retrak currently provides such parenting skills as part of their rehabilitation 
services to reunite street boys with their families. However, these services would offer greater value if provided on an ongoing basis to the larger community in order to improve the well-being of young people and their families.

- Government social workers and counselors should collaborate with NGOs and other civil society organizations to offer greater recognition and support to marginalized youth to address the overwhelming psychosocial needs observed in this study. Several government and community wide organizations such as idirs (well-established community support groups), local government and kebele (ward/neighborhood) officials, and the Regional Bureaus of Women Children and Youth Affairs are tasked with reaching out to youth with support services. Many are already working with service delivery NGOs and may serve as leaders in addressing social issues surrounding adolescent migrants. This may be a timely collaboration particularly for Biruh Tesfa, given the transition of the program's administration. Walk-in community mental health services such as the Empilweni in South Africa may provide an alternative, accessible, and appropriate model to professional mental health clinical care (Empilweni 2010). In this model (operated primarily by social workers, community workers and lay persons trained on case studies) parents, and children alike are educated about common adolescent mental health and psychosocial problems often resulting from sexual abuse, effects of HIV infection, and antisocial behavior.

- Several study respondents expressed their belief that child abusers are rarely punished and often treated with impunity. This sentiment has also been echoed in literature regarding the impunity of sexual abuse perpetrators in Ethiopia (Yntiso et al. 2009). Organizations that work directly with marginalized youth should consider conducting outreach programs to offer information, awareness, and legal support to victims of child abuse so they can feel empowered to take action against their abusers.

- Further research should be conducted in order to better understand the factors facilitating the process and outcomes of child migration and how they can be addressed. In particular, it would be important to learn more about facilitators of migrations, including agents who are responsible for accompanying and receiving young adolescents to and in Addis Ababa (Van Blerk 2008). 


\section{REFERENCES}

Andrés, M., M. Catalá, and M. Gómez-Beneyto. 1999. "Prevalence, comorbidity, risk factors and service utilisation of disruptive behaviour disorders in a community sample of children in Valencia (Spain)," Soc Psychiatry Psychiatr Epidemiol 34: 175-179.

Ashenafi, D. et al. 2000. "Socio-demographic correlates of mental and behavioural disorders of children in southern Ethiopia,” East African Medical Journal 77(10).

Azjen, I. 1991. "The theory of planned behavior," Organizational Behavior and Human Decision Processes 50: 179-211.

Bollinger, A. 2010. "How communication can lead to change: giving girls a safe space to speak through a Stepping Stones programme in Uganda," presentation at Children and HIV: Family Support First Symposium, Vienna, Austria, 16-17 July.

Crouch, M. and H. McKenzie. 2006. "The logic of small samples in interview-based qualitative research." Social Science Information 45: 483-499.

Desta, M. 2008. “Epidemiology of child psychiatric disorders in Addis Ababa, Ethiopia.” Umeå, Sweden: Division of Child and Adolescent Psychiatry Department of Clinical Sciences, Umeå University.

Empilweni Place of Healing. 2010. www.empilweni.org.

Erulkar, A. et al. 2006. "Migration and vulnerability among adolescents in slum areas of Addis Ababa, Ethiopia," Journal of Youth Studies 9(3): 361-374.

Erulkar, A. and A. Ferede. 2007. "Social exclusion and early or unwanted sexual initiation among poor urban females in Ethiopia," International Perspectives on Sexual and Reproductive Health 35(4).

Erulkar, A. and T. Ab Mekbib. 2007. "Invisible and vulnerable: Adolescent domestic workers in Addis Ababa, Ethiopia," Vulnerable Children and Youth Studies 2(3): 246-256.

Green, J. M. and N. Thorogood. 2004. Qualitative Methods for Health Research. London: Sage Publications Ltd.

Hagos, B. 2006. "Sexual abuse and exploitation of male children in Addis Ababa." Addis Ababa: Save the Children and Denmark and Bright for Children Voluntary Association.

Implementing Stepping Stones. 2007. A Practical and Strategic Guide for Implementers, Planners and Policy Makers. Agency for Co-operation and Research in Development (ACORD).

Interagency Coalition on AIDS and Development (ICAD). 2006. HIV/AIDS and Gender Issues.

International HIV/AIDS Alliance. 2003. "Building blocks: Africa wide briefing notes—Psychosocial support." Brighton, UK: International HIV/AIDS Alliance.

Kay, L. 2012. "Mental health formative study data interpretation meeting," personal communication, November 29.

Last, C. et al. 1996. "A prospective study of childhood anxiety disorders," J Am Acad Child Adolesc Psychiatry 35: 1502-1510. 
Lakew, Z. 2001. "Alleged cases of sexual assault reported to two Addis Ababa hospitals," East African Medical Journal 78(2): 80-83.

MEASURE DHS and ICF Macro. 2011. "Ethiopia Demographic and Health Survey (EDHS): Preliminary report." Central Statistical Agency Addis Ababa, Ethiopia. Calverton, Maryland, USA: MEASURE DHS, ICF Macro.

Melesse F. and Kassie, A. 2005. "Child abuse in urban setting: a one-year analysis of hospital information on abused children at Yekatit 12 hospital, Addis Ababa," Ethiop Med J. 43(4): 223-232.

Molla, M. et al. 2002. "Sexual violence among female street adolescents in Addis Ababa, April 2000," Ethiopian J. Health Dev. 16(2): 119-128.

Moore, A., et al. 2007. "Coerced first sex among adolescent girls in sub-Saharan Africa: Prevalence and context," African Journal of Reproductive Health 11(3): 62-82.

Schenk, K. D. and J. Williamson. 2005. Ethical Approaches to Gathering Information among Children and Adolescents in International Settings: Guidelines and Resources. Washington DC: Horizons/Population Council, Family Health International/ Impact, United States Agency for International Development.

Tadele, G. 2009. “'Unrecognized victims': Sexual abuse against male street children in Merkato area, Addis Ababa," Ethiopian Journal of Health Development 23(3).

Temin, M. et al. 2013. Girls on the Move: Adolescent Girls and Migration in the Developing World. New York: Population Council.

United Nations (UN). 2003. World Youth Report: The global situation of young people. Chapter 4 Youth and Health Issues. New York: United Nations.

UNAIDS. 2013. "Global report: UNAIDS report on the global AIDS epidemic 2013.” Geneva: UNAIDS.

UNAIDS. 2012. "Country progress report on HIV/AIDS 2012: Federal Democratic Republic of Ethiopia." Addis Ababa: Federal Democratic Republic of Ethiopia.

Van Blerk, L. 2008. "Poverty, migration and sex work: Youth transitions in Ethiopia," Area 40(2): 245-235.

WHO. 2003. "Caring for children and adolescents with mental disorders. Setting WHO Directions." Geneva: WHO.

WHO. 2008. "HIV/AIDS and mental health: Report by the Secretariat" Geneva: WHO.

Yntiso, G. et al. 2009. "The bamboo project: Resilience in children exposed to sexual abuse and sexual exploitation in Merkato, Addis Ababa, Ethiopia.” Addis Ababa: Oak Foundation. 


\section{APPENDICES}

\section{ANNEX A-SERVICE RECIPIENT IN-DEPTH INTERVIEW GUIDE}

\section{Service Recipient In-depth Interview Guide}

Adapted from Sweta Shah et al. 2005'; UN Sexual Abuse Report 2000i; and IOM Psychosocial Needs Assessment Tools 2010iii

Instructions for interviewer:

This tool should be administered to selected service recipients at Biruh Tesfa and Retrak. As per the study criteria, the interviewee must be between the ages of 15-24 and have been an active client at the service organization for the past three months.

Participant Study ID Number: COO 
Section I. Service Recipient Background

\begin{tabular}{|c|c|c|c|}
\hline No. & Questions & Responses - Codes & $\begin{array}{c}\text { Skip } \\
\text { patterns }\end{array}$ \\
\hline Q01 & INDICATE SEX OF RESPONDENT. & Male & \\
\hline Q02 & $\begin{array}{l}\text { Which organization do you receive } \\
\text { regular services from? } \\
\text { CIRCLE ALL THAT APPLY. }\end{array}$ & 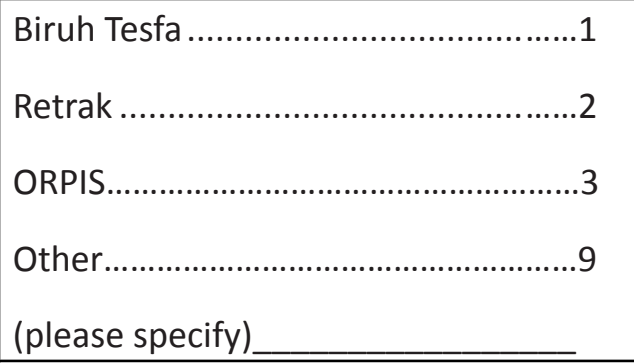 & \\
\hline Q03 & $\begin{array}{l}\text { How long have you been receiving } \\
\text { services from this organization } \\
\text { mention in Q02? } \\
\text { DO NOT READ RESPONSES. PROBE. }\end{array}$ & 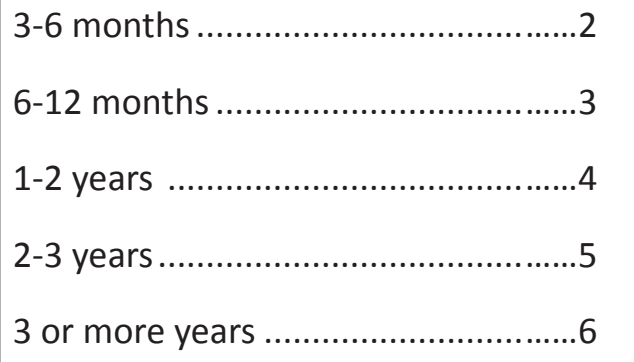 & \\
\hline Q04 & $\begin{array}{l}\text { WAS RESPONDENT REFERRED TO } \\
\text { COUNSELOR AT ANY POINT DURING } \\
\text { THE INTERVIEW? }\end{array}$ & If yes please provide detailed explanation & \\
\hline
\end{tabular}


Section II. Open-ended Questions

\section{Details about self}

1. Please tell me about yourself.

Probe using the following questions:

How old are you?

Where in Ethiopia are you from?

2. Let me know about your schooling experience

Probe using the following questions:

Do you currently go to school?

Did you go to school before?

If you stopped, why did you stop?

What level of schooling have you so far achieved?

Do you like school?

\section{Please describe your present living conditions}

Probe using the following questions:

What kind of place do you sleep in?

Are you living on the street? If so why are you living on the streets?

How did you find this place?

How long have you lived in this place?

Are you sharing this place with other people?

How is your relationship with the people you share this place with?

Are you living in a home with some people? If so how did you begin living there?

What is your relationship with the owner of the home?

How do you feel about this place?

Some young people may get hurt by the people they live closely with while others experience a positive living environment.

Do you feel safe in this place?

Please give me three words that describe your life in this place

4. Let me know about your family situation

Probe using the following questions:

Some young people living in the city have lost contact with their family while others maintain communication with their family.

Do you have contact with your family? If not why do you not have contact with them?

Do you ever think of returning to your family?

Do you ever return to your family? If so how often do you visit your family?

5. Tell me about your social life and recreation

Probe using the following questions:

What do you like to do? What is your favorite activity?

Who are your friends? Are they the same age as you? With whom do you play? What is your

favorite game? 
Who is the person you wish to spend time most with? How often do you see him/her?

Are you involved in any groups with other young people? Is so, how did you find them? Why did you get involved?

What makes you happy?

\section{Tell me how you respond to problems, distress or uneasiness?}

Probe using the following questions:

Some young people get frustrated or disappointed for various reasons.

Do you ever feel angry or sad? If so, what makes you angry or sad? How often do you feel sad during a day?

Do you have someone to turn to for support when in need?

\section{Let me know how you earn your living}

Probe using the following questions:

Are you working? Is so, how did you find this job?

How long have you been working?

What kind of work do you engage in?

What do you like/dislike about your work?

How much money do you earn on a monthly/daily basis?

Some young people are in job situations where they feel they are staying voluntarily while others feel forced to stay in those job situations.

In your job situation can you leave if you wish to?

What are your daily activities from the moment you wake up to the time you go to sleep?

Do you have a day off? How do you spend your free time?

Some people working may share their earnings with friends or relatives.

Do you share the money you earn with others? How much and how often?

Do you send any money to your parents/family and if so how much?

Do you feel forced to share your earnings with others? If so, with whom?

Now we are going to talk about something private.

8. Can you tell me about your sexual life

Probe using the following questions:

Have you ever had sexual intercourse?

Sometimes young people are forced into sexual intercourse while others engage in sex willingly. We would now like to know whether the first time you had sex was it forced or were both of you willing?

If forced, did you force someone or did someone force you? Who was this person?

How many people did you have sex with last month? Please describe them. What ages were they? Were they men or women?

Often people engage in various types of sexual intercourse such as oral, vaginal, or anal sex. What kinds of sexual intercourse have you ever been engaged in? Have you ever had oral, anal or vaginal sex? 


\section{Sometimes money is exchanged in return for sexual services.}

Have you ever paid money for sex? What kind of person did you pay for sex? Male or female? Older or younger? Sex worker, friend, lover?

Have you ever been paid money or materials goods for sex? What kind of person paid you for sex? Male or female? Older or younger? Sex worker, friend, lover?

There are various forms of engaging in safe.

Do you use condoms during sexual encounters?

If no, why?

If yes, do you use them all the time or only with some people? If selective, which people and why?

There are several consequences of engaging in unprotected sexual intercourse.

Have you ever been pregnant or made someone pregnant?

What did you do?

Probe for the decision to abort or deliver the child and how it was made.

Have you suffered from STDs previously?

Did you seek care? Where? What was the reaction of your friends, family members and service providers?

Have you heard of HIV? Do you know how it is transmitted?

Have you ever been tested for HIV? Do you feel you need to be tested for HIV?

Now I would like to talk about some difficult personal experiences you may or may not have faced.

9. Tell me about any situations when you have been mistreated or abused physically or sexually. Probe using the following questions:

Have you been physically or sexually abused? By whom? How and where did it happen?

At what age were you sexually or physically abused?

Were any of your family members or close friends and relatives involved in the abuse? How?

Currently do you feel you are being sexually or physically exploited by someone?

What type of physical or sexual exploitation are you going through?

\section{What is your experience with use of alcohol or other substances?}

Probe using the following questions:

Have you ever taken alcohol or any substances? Do you take any currently? If yes, which ones?

What is/are the slang name(s)? How do you take the substance(s)? Drink? Smoke? Sniff?

How frequently do you use it/them?

Do you think boys and girls use these substances differently and if so what effect do you think this has on their sexual behavior?

\section{What are your medical, psychological and social needs?}

Probe using the following questions:

Apart from lack of money and material things such as food, clothing and shelter, what other

things give you distress or uneasiness?

Can you tell me the most important of these concerns?

Can you state three wishes that are most important to you? 
Now I would like us to talk about the services that you are receiving

12. Please tell me about services or programs that respond to your personal needs. These can include medical services, food, shelter, clothing, schooling, counseling, legal help.

Probe using the following questions

Please name the programs that you have ever received these types of services from.

Do you like these programs that you participate in? If so, why do you like it? Which ones are your favorite?

How are your needs/complaints handled by caregivers?

How do you know about these facilities?

When do you use these services? Health clinic? Drop-in centre? Rehabilitation centre?

How frequently do you visit these services?

What do you get in terms of services, supplies and advice when do you go there?

Are there services you do not go to?

If yes, why? If no, why? Probe for accessibility and acceptability.

What would you suggest for improving the situation?

In your view how can your needs best be addressed?

What kind of help would you wish to have?

13. Before we end our conversation please tell me your expectations for the future and how you think the suffering of young people like you can be reduced

Probe using the following questions

What do you hope to do in the future?

What are your dreams and future aspirations?

Do you have any recommendations to prevent sexual exploitation and abuse of young people like you?

What measures should be taken to help victims at various stages of physical and sexual abuse?

Thank you very much for your time in providing your responses to this interview. As mentioned before during the consent process, we plan on using the information you provided today to improve the well-being of young people like you.

\footnotetext{
'Sweta Shah et al. (2005). "Youth on the streets: the importance of social interactions on psychosocial well-being in an African context." Washington, DC: George Washington University. http://cfsc.trunky.net/ uploads/Publications/13.Youth on the Streets.pdf

i UN. (2000). "Economic and Social Commission for Asia and the Pacific-Sexually abused and sexually exploited children and youth in the Greater Mekong Subregion: A qualitative assessment of their health needs and available services." New York: United Nations http://www.unescap.org/esid/hds/sexual/gms.pdf

iii'IOM. (2010). Psychosocial Needs Assessment in Emergency Displacement, Early Recovery, and Return IOM Tools. International Organization for Migration (IOM).

http://www.iom.int/jahia/webdav/shared/shared/mainsite/activities/health/mental-health/Psychosocial-NeedsAssessment-Emergency-Displacement-Early-Recovery-Return-IOM-Tools.pdf
} 


\section{ANNEX B - SERVICE PROVIDERS IN-DEPTH INTERVIEW GUIDE}

\section{In-depth Interview Guide for Service Providers}

Instructions for interviewer

This tool should be administered to staff involved in providing services to young people being served by Biruh Tesfa and Retrak. This will include counselors and the nurse at Retrak; counselors at OPRIS; mentors at Biruh Tesfa.

Participant Study ID Number: $P$

Section I. Health Care Provider Background and Experience

\begin{tabular}{|c|c|c|c|}
\hline No. & Questions & Responses-Codes & $\begin{array}{c}\text { Skip } \\
\text { patterns }\end{array}$ \\
\hline Q01 & $\begin{array}{l}\text { What is your current job(s) in the } \\
\text { facility or organization? } \\
\text { DO NOT READ RESPONSES. PROBE. } \\
\text { CHECK ALL THAT APPLY. }\end{array}$ & 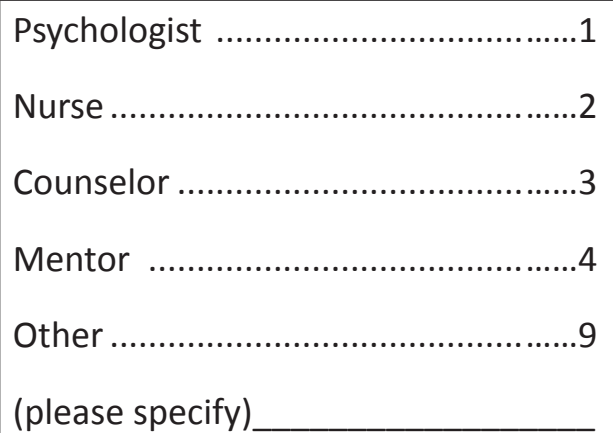 & \\
\hline Q02 & $\begin{array}{l}\text { In which organization do you work? } \\
\text { CIRCLE ALL THAT APPLY. }\end{array}$ & 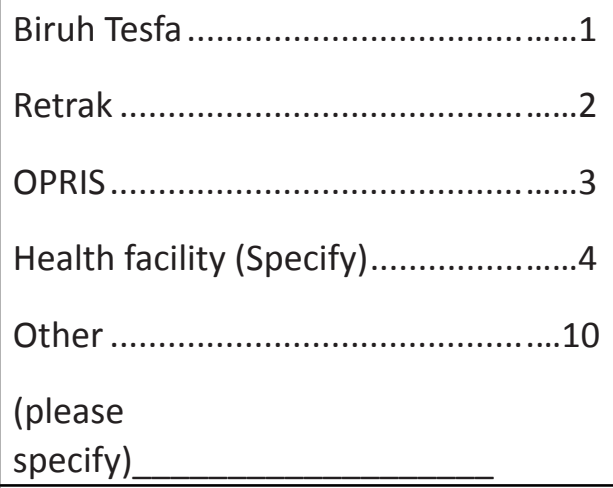 & \\
\hline Q03 & $\begin{array}{l}\text { How long have you been working } \\
\text { with this organization mention in } \\
\text { Q02? }\end{array}$ & 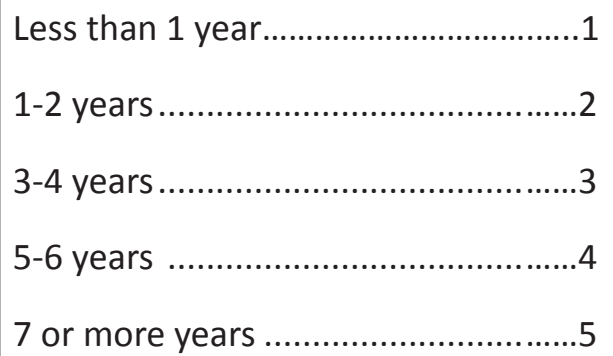 & \\
\hline
\end{tabular}




\section{Section II. Open-ended Questions}

In answering the questions below please respond based on the behavior of the children you have been working with in the past six months.

1. To begin with please explain to me the service you provide to young people participating in Biruh Tesfa or Retrak?

Probe using the following questions:

a. Where is your work station?

b. Do the young people come to your office/facility to receive services or do you sometimes go to them at their residence or place of work?

c. Approximately/About how many young people do you serve in a day?

2. Please describe what your know about the living conditions of the young people you serve Probe using the following questions:

What kind of place do they sleep in?

If they live in homes, do they live with parents, relatives, guardians or are they live-in house helps?

3. What do you know about the family situation of the children you serve?

Probe using the following questions:

Do some of them have contact with their family?

Do some ever return to their family?

Do (m)any have any intention of returning home?

4. How much of a social life and recreation do they have?

Probe using the following questions:

How do your beneficiaries spend their spare time?

Do some of them have friends with whom they always spend time most?

Do you know if they play games?

What kind of games do they seem to like?

5. How do they cope with problems, distress or uneasiness?

Probe using the following questions:

What kinds of things make them angry or sad?

Who do they to turn to for support when in need?

6. How do they earn their living?

Probe using the following questions:

Are some of them working? If so, what type of work do they tend to do?

Do they usually have some free time off from work?

For those who work what is the range of their income monthly/daily?

Do you think some of them send some money home to the family they left behind? 


\section{What do you know about their sexual life?}

Probe using the following questions:

What proportion do you think have ever had sexual intercourse?

Do you think some of them are being coerced or forced to have sex?

Do you think some of them sell or buy sex?

Do you think many of them use condoms during sexual encounters?

How frequent are pregnancies among these young people?

How do most of these pregnancies end, do they end in abortion or live birth?

How many of these young people are aware of HIV and understand how it is transmitted?

How many have been tested for HIV?

8. How is the situation with regard to use of alcohol or other substances?

Probe using the following questions:

For those who drink, how much and what kind of alcohol is consumed?

For those who use drugs what kinds and how often do they use?

What are some of the common names of alcohol or substances they are using?

9. How would you describe the medical, psychological and social needs of these children?

Probe using the following questions:

Apart from lack of money and materials things such as food, clothing and shelter, what other

things give them distress or uneasiness?

Can you tell me the most important of these concerns?

What do you think should be done to address these needs?

10. Please tell me about services or programs that are responding to the needs of these young people. These can include medical services, food, shelter, clothing, schooling, counseling, legal help.

Probe using the following questions:

How adequate are these services in addressing the children's' needs?

What areas require strengthening?

11. Before we end our conversation please tell me how you think the suffering of young people like these can be reduced?

Probe using the following questions:

What are your recommendations on improving current service delivery to better address the needs of these young people?

Do you have any recommendations to prevent sexual exploitation and abuse of young people such as these?

What measures should be taken to help victims at various stages of physical and sexual abuse?

12. Please tell us what you know about the dreams/aspirations of these young people. 
U.S. Agency for International Development I 300 Pennsylvania Avenue, NW

Washington, DC 20523

Tel: (202) 7I2-0000

Fax: (202) 216-3524

www.usaid.gov 